\title{
How renewable energy affects our planet's future?
}

\author{
${ }^{1}$ Udit Veerendra Bagdai, BNMIT,udit18me053@ bnmit.in 22Rahul B, BNMIT, rahul18me033@bnmit.in \\ ${ }^{3}$ Raksha Channappa, BNMIT, raksha18me035@bnmit.in ${ }^{4}$ Sanjay B Y, BNMIT, sanjay18me042@bnmit.in \\ ${ }^{5}$ Champa PN, Assistant professor, Department of EEE, BNMIT, champapn@ bnmit.in
}

\begin{abstract}
Renewable energy is considered an infinite source of energy. Although they have unlimited potential towards making our environment self-sustainable, they are currently insufficiently exploited and unevenly distributed. The major hindrance to exploiting these renewable sources is economic issues. Some countries, that possess these sources are currently developing or are still in the under-developed scenario. Hence, these resources are not being exploited to their full potential. We are aware of the severe consequences of burning up fossil fuels and their adverse effect on our environment.

Rarely do we think of the consequences on the environment due to renewable energy sources. Although they have a very small impact on our environment, in the future it might lead to some devastating issues. Some of the renewable energy sources have a visual impact on the nature of our earth and also to some extent it can affect the ecosystem of a particular area. This paper intends to analyze the current types of renewable sources (solar, wind, geothermal and hydroelectric) and their impact on our planet.
\end{abstract}

\section{I-Introduction}

World Energy has estimated that in another 10 decades' fossil fuels would have been exhausted on our planet ${ }^{[1]}$. This implies we must find other alternative sources of energy to continue living on our planet. Hence, researchers and scientists over the decades are on the search for alternate sources of energy. But these sources must also be harmless to the environment since climate change and global warming are also major threats to our planet. The precise effects of these sources vary based on the resource being exploited, nevertheless, by carefully analyzing the current and probable issues caused by these resources to our environment, we can minimize the effect on the planet.

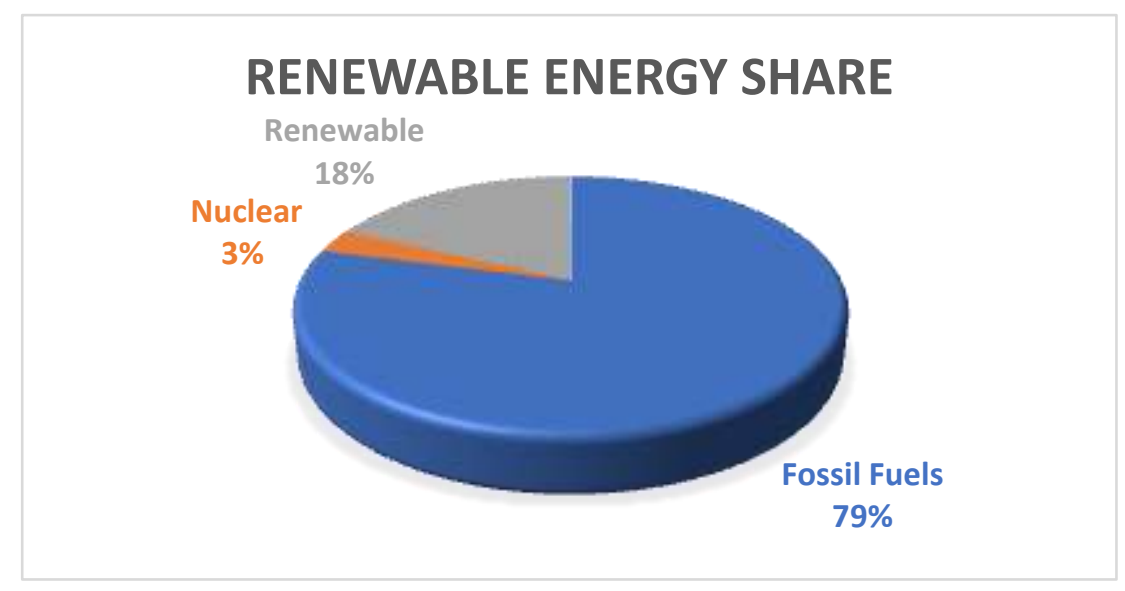

Figure 1: Renewable Energy Share 
Figure 1 shows the current scenario, renewable sources power up $18 \%$ of the energy needs in the world. In this, biomass contributes up to $13 \%$ as it is being used in cooking and heating; as it is considered to be efficient and easily available. ${ }^{[1]}$ Our objective must be to increase the percentage of renewable energy used to power up life on our earth. Hence, the process of developing renewable sources must be taken on a serious note.

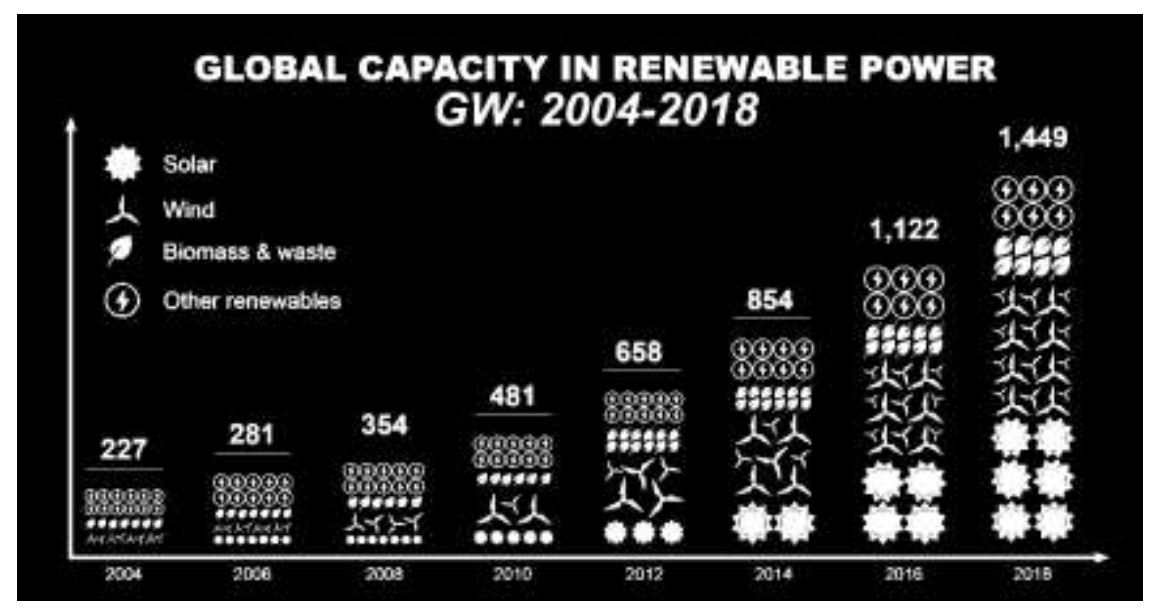

Figure 2: Global capacity of renewable over the past years

Figure 2 depicts the growth of global renewable energy over the years, from this it is clear that renewable sources have rocketed over the years, especially in the past decade. Solar and wind energy are the main components of renewable. Based on this trend the growth of renewables is the future.

Generating energy from wind is considered one of the cleanest and most sustainable approaches. Also, wind is abundantly available, clearly affordable and limitless. Despite these several boons, they cause land issues and difficulties to the natural habitat. Similar to wind energy, solar is considered a sustainable source for producing energy. However; issues like habitat loss, use of hazardous materials like silicon and huge amounts of water to be used have a severe impact on the environment ${ }^{[2]}$. Geothermal energy can cause the tectonic plates to move, causing earthquakes and tsunamis. Moving on to hydroelectric power generation, this requires a huge amount of land to be revamped.

\section{II - Literature Survey}

In this paper, we have focussed on four major renewable energy sources, where will depict the harmful effects of these on our planet and how they might affect our future. The following are the renewables we have concentrated on:

1. Solar Energy

2. Wind Energy

3. Geothermal Energy

4. Hydropower Energy 


\section{Solar energy}

Solar power generation does not produce any air pollution while generating power. However, the materials used in the production of solar production systems can health issues to the workers how come in close contact with them. To be specific, the manufacturing of photovoltaic cells consists of toxic materials like Cadmium and Arsenic. Although Silicon is considered relatively inert if breathed in can be fatal. ${ }^{[3]}$

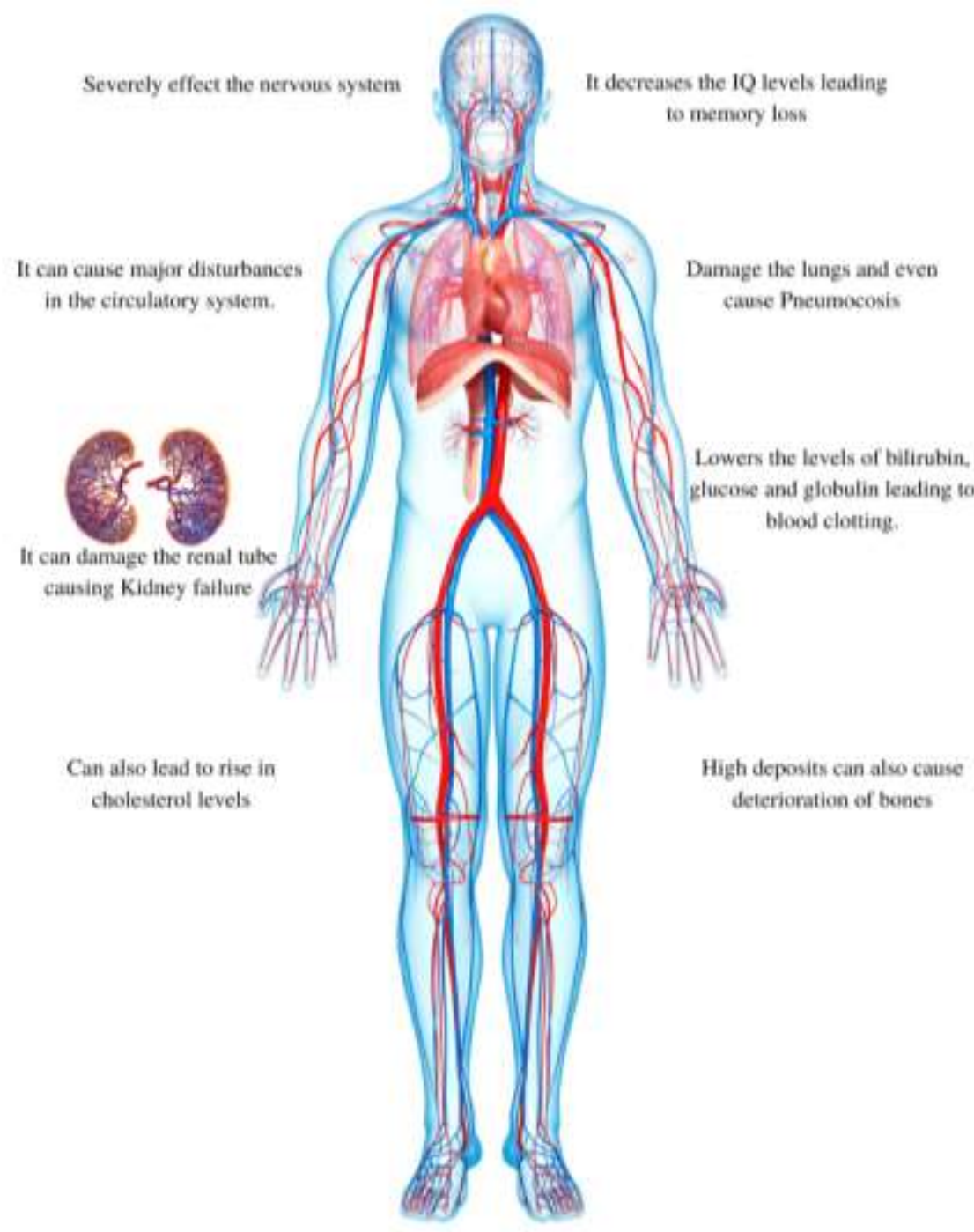

Figure 3: Adverse effects of rare earth metals on the human body

Figure 3 denotes the effects of several rare earth elements on a human body, as solar requires several types of rare earth elements, the effects are devastating. In some cases, it might even lead to severe complications leading to the death of an individual. Damage caused to vital organs like the heart, lung and brain is almost irreversible in the medical field today. Although there have been advancements in the medical field which have been significant to life on earth, some things are out of the hands of medical professionals. 
Furthermore, they also require huge amounts of water to act as coolants depleting the habitat's natural resources. To generate sufficient amounts of electricity, solar must be implemented in a large-scale manner. This disrupts the thermal balance of a particular area by absorbing more energy from the earth than otherwise would be reflected by the surface back to space. These components contain harmful elements and there is a potential risk of these harmful chemicals getting released into the atmosphere in case of fire incidents. As solar contributes close to around $6.4 \%$ of the energy produced on the planet, we need to ensure its adverse effects don't cause serious damage to the environment. ${ }^{[4]}$

\section{Wind Energy}

Although, it produces no water or air pollution and almost involves no toxic substances in its production they have quite a serious impact on wilderness areas. The noise coming out of the turbine is also quite considerable, it can be matched to that of a small jet engine. This is feasible only if there are no settlements located in close vicinity of the turbine. The main factors contributing to noise are the aerodynamic noise due to the air passing over the blades and mechanical noise due to the moving parts of a turbine-like its Gearbox or other mechanical components. To add on, some people have also complained about the vibrations causing them severe headaches. ${ }^{[5]}$

Additionally, these wind turbines also might scatter electromagnetic waves or signals causing major interference to communication systems. Besides this, birds too get killed when they come in contact with these turbines.

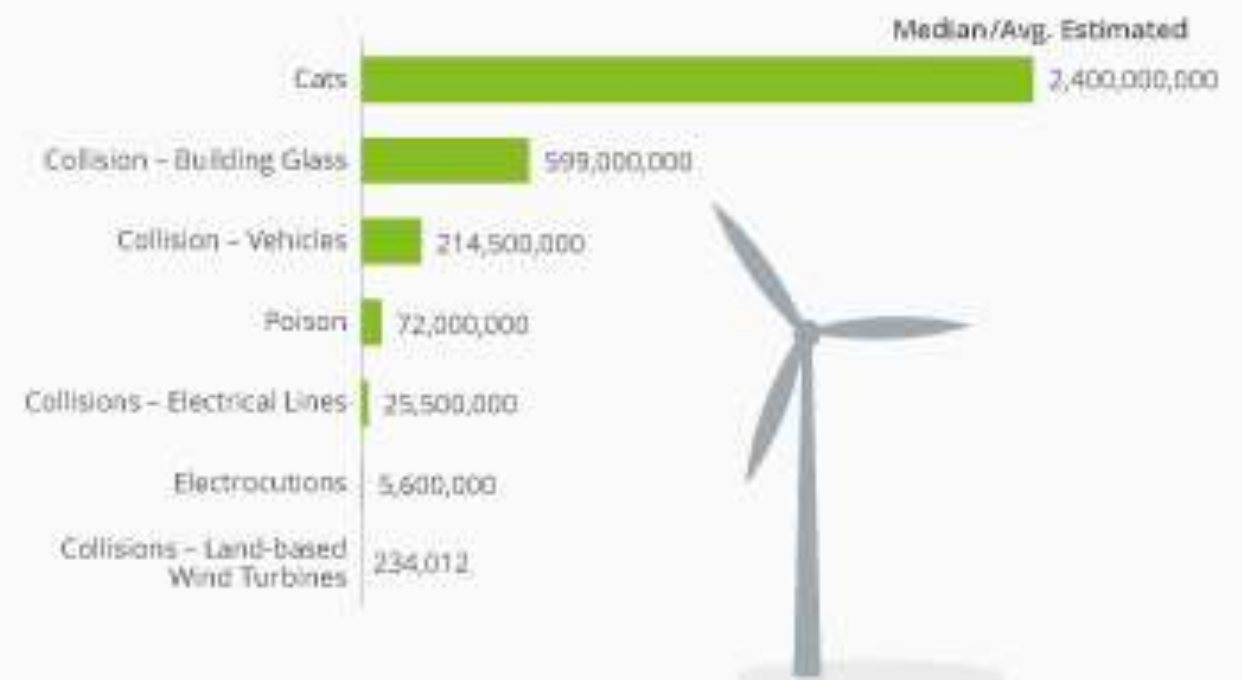

Figure 4: Bird deaths due to several factors

Figure 4 depicts the bird deaths in the United States due to several causes in the year $2017^{[9]}$. This image tells us the number of bird deaths caused due to turbines was around 200,00. This is a devastating number, as this is only a number in the United States, well a study published by ornithologist K. Shawn Smallwood found that wind turbines killed an estimated 573,000 birds annually in the world ${ }^{[5]}$. The death of several birds can have serious implications on the food cycle, pollinating agents and several other biotic components. 


\section{Geothermal power}

Geothermal energy is obtained from the heat present below the earth's crust, hence for easy extraction of these powers geothermal plants are present at geological hotspots because at these regions the hot molten rock is situated close to the crust. In other regions, it is considered rather difficult since it involves drilling through the earth's surface. These plants differ in the method used to produce energy, but overall require huge amounts of water or air for cooling purposes.

These geothermal plants can cause adverse surface disturbances to the land surrounding the plant, noise, thermal pollution and releases harmful substances into the atmosphere. Additionally, when hot water or steam passes over the rocks present below the crust it can cause several hazardous gases to leech out into the atmosphere like Boron, Arsenic and Mercury ${ }^{[3]}$. These substances can have adverse effects on the human body and can also be fatal in some cases.

As stated earlier, based on the type of the geothermal plant water or air must be used for cooling. In the case where water must be used, great amounts of water must be used for cooling. This might not be a major concern if there is a plentiful supply of water, but in some places, water is not readily available it can cause a scarcity issue. Also at The Geysers, one of the largest geothermal power plants steam vented off beneath the surface containing Hydrogen Sulphide, Ammonia, Methane and huge amounts of Carbon-di-oxide.

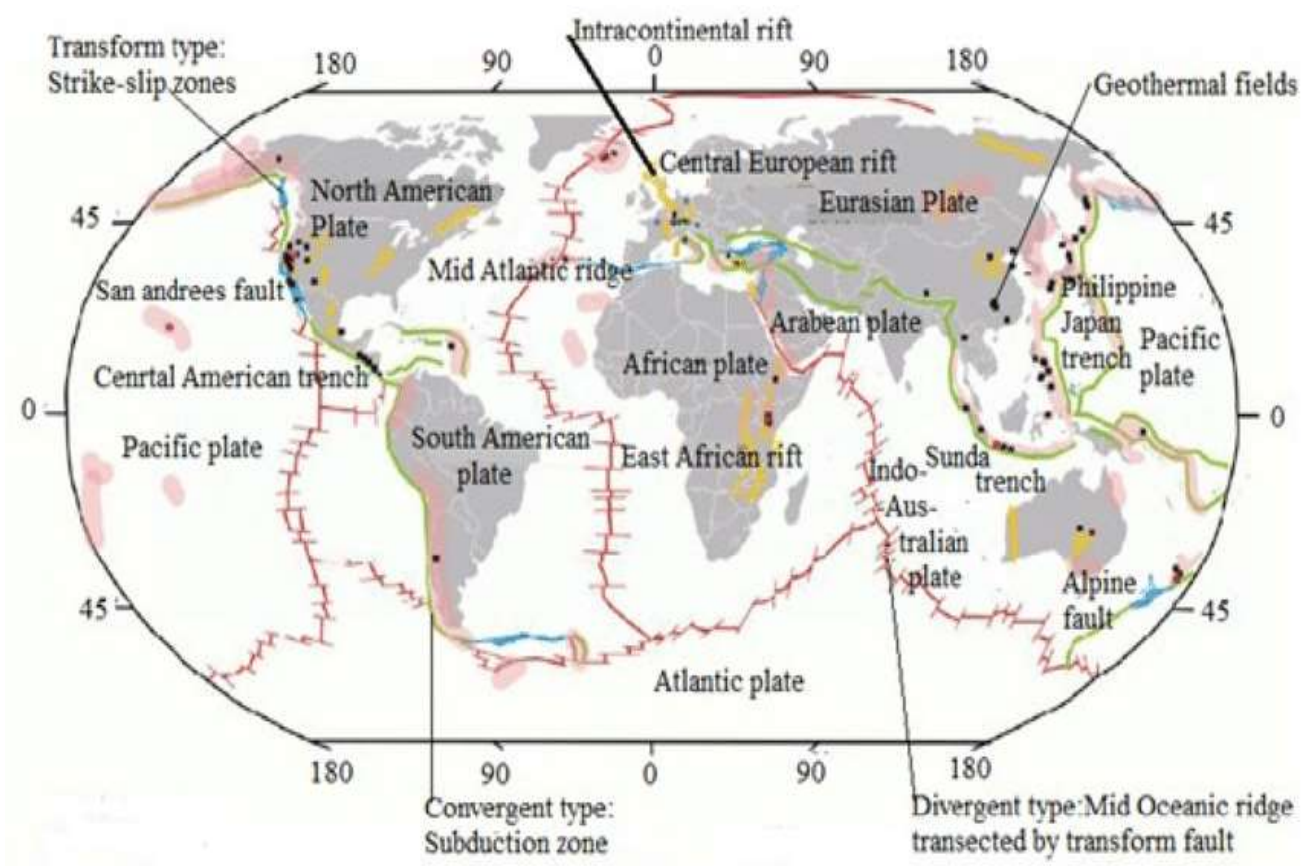

Figure 5: Worldwide geothermal fields related to tectonic plates

From figure 5 we can notice geothermal spots are usually located at the edge of a tectonic plate ${ }^{[11]}$. When situated at these areas the risk for unnecessary tectonic movement comes in. These geothermal plants can cause tectonic activity which in turn could cause earthquakes, tsunamis, volcanoes to erupt. This can also occur if the holes are drilled in the wrong manner, this would not only cause a catastrophe but can also lead to the release of several hazardous substances present beneath the earth's surface 


\section{Hydropower}

Hydropower involves the production of energy from the potential energy of water. It mainly involves the construction of huge dams and reservoirs. Currently, it contributes to about $8 \%$ of the energy being produced worldwide ${ }^{[1]}$. Large hydel projects have unfavorable impacts on the environment, especially on water also, it affects the biotic habitat of a certain place. They can disrupt the local ecosystems, damage marine life and also dampen the quality of the water.

In addition to this, hydel projects also cause socio-economic damage by forcing local inhabitants to relocate. This could severely affect the minds of the people, forcing them to take up wrong steps. Apart from this, several projects around the world particularly in underdeveloped or developing countries the projects have been halted or terminated midway due to economic difficulties. This makes the land unfeasible for either power generation or for what it was meant beforehand.

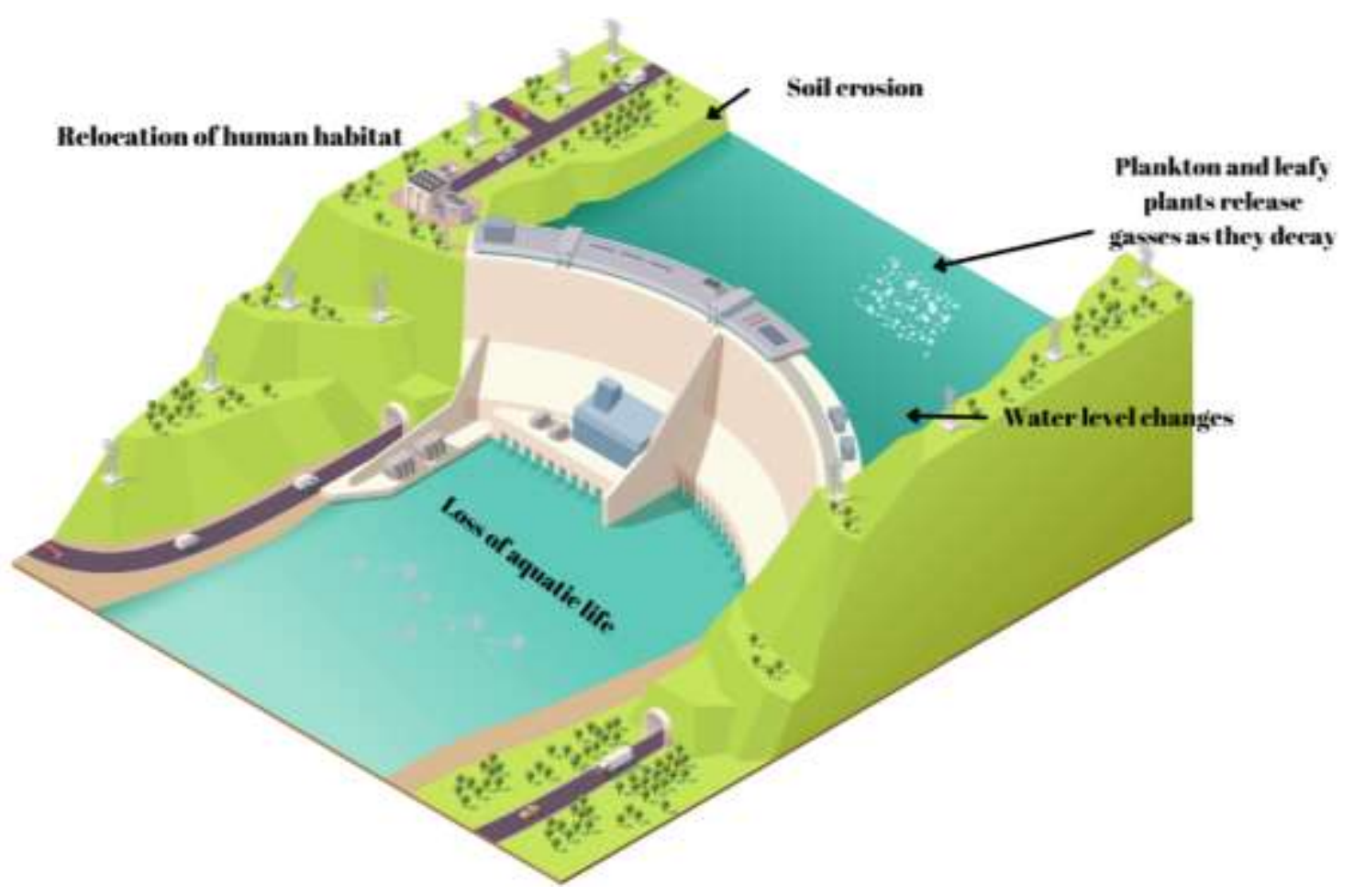

Figure 6: Pictorial representation of adverse effects caused to the environment

Furthermore, hydel power emits greenhouse gases namely Methane; ${ }^{[2]}$ which is generated from the decaying bioenergy present in these reservoirs. Although currently, it is a very small amount, in the upcoming future when the number of hydel projects increases, these emissions might also tend to increase, harming our environment. 


\section{III- Analysis}

Although renewable energies are considered less harmful than conventional sources their emissions have a major contribution to the environment. Namely, there are many emissions of Carbon dioxide $\left(\mathrm{CO}_{2}\right)$, Methane $\left(\mathrm{CH}_{4}\right)$, Nitrous oxide $\left(\mathrm{N}_{2} \mathrm{O}\right)$, Sulphur dioxide $\left(\mathrm{SO}_{2}\right)$ and many other harmful emissions.

But the most harmful and noticeable emissions are $\mathrm{CO}_{2}, \mathrm{SO}_{2}$ and $\mathrm{NO}_{\mathrm{x}}$. These are considered to be the most harmful; Carbon dioxide can have a severe toll on one's health. It can cause headaches, difficulty in breathing, increased heart rate, dizziness and even coma. $\mathrm{CO}_{2}$ also increases the greenhouse effect; it has a key part in depleting the ozone layer.

Sulphur dioxide and several oxides of Nitrogen can cause major respiratory tract-related issues, it can severely damage the functioning of the lungs. Besides health issues, it can harm trees and plants by damaging foliage and decreasing growth ${ }^{[8]}$.

\begin{tabular}{|l|l|l|l|l|l|}
\multicolumn{2}{|c}{$\begin{array}{l}\text { Hydropower } \\
\text { Small scale }\end{array}$} & $\begin{array}{l}\text { Hydropower } \\
\text { Large scale }\end{array}$ & Solar energy & Wind energy & $\begin{array}{l}\text { Geothermal } \\
\text { Energy }\end{array}$ \\
\hline $\mathbf{C O}_{2}$ & 9 & $3.6-11.6$ & $98-167$ & $7-9$ & 79 \\
\hline $\mathbf{S O}_{2}$ & 0.03 & $0.09-0.024$ & $0.2-0.34$ & $0.02-0.09$ & 0.02 \\
\hline $\mathbf{N O}_{\mathbf{x}}$ & $0.003-0.006$ & 0.07 & $0.18-0.30$ & $0.02-0.06$ & 0.28 \\
\hline
\end{tabular}

Table 1: Life cycle air emissions from renewable energies $(\mathrm{g} / \mathrm{KWh})$

This suggests the emissions of renewable energies in terms of life cycles ${ }^{[9]}$. From the above table, it can be noted that the emissions caused by solar photovoltaic are the most and hence very dangerous to our environment.

Although the emissions produced by hydropower are comparatively lesser than that of Solar or even maybe Geothermal it too has a big impact on our planet in the future.

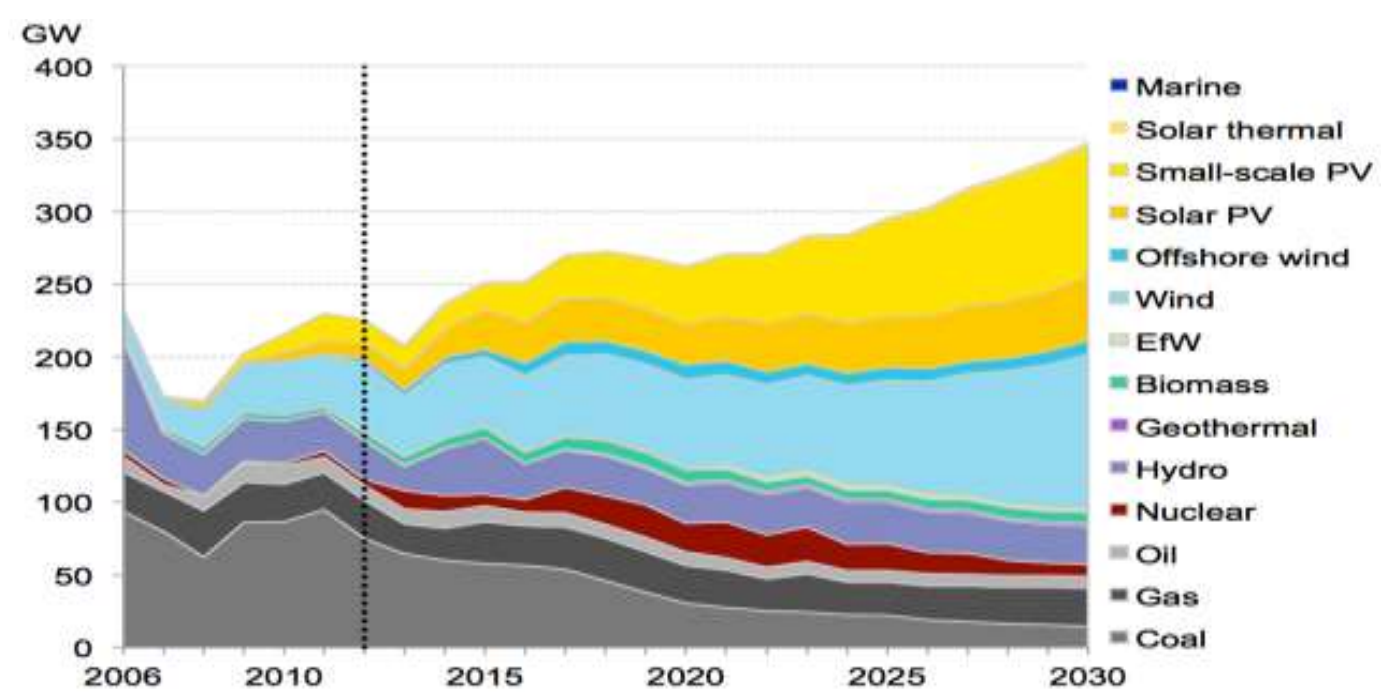


Figure 7: Prediction of renewables in the coming decades

Figure 7 predicts the growth of renewable energies in the upcoming years throughout the world. It is visible that the estimated growth of solar photo-voltaic cells is drastic. By the end of 2030, the energy of solar cells would almost increase by two folds. The emissions and harmful effects that would occur due to solar are alarming. Besides solar; wind energy is also expected to increase by almost $40-50 \%$ which could have devastating issues as discussed earlier.
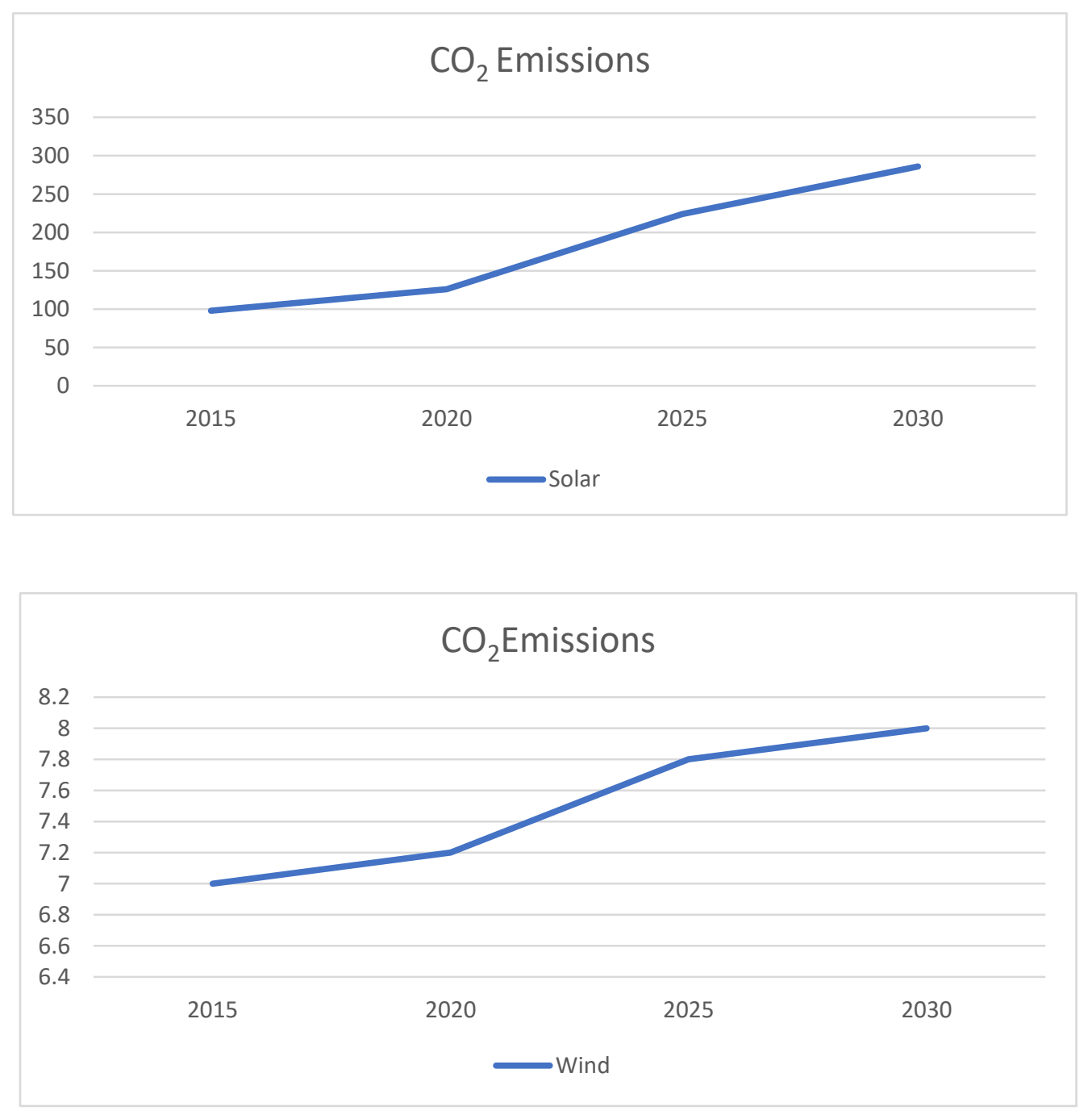

Figure 8: Prediction of $\mathrm{CO}_{2}$ Emissions in the coming years

Figure 8 depicts the $\mathrm{CO}_{2}$ emissions in the coming years, this data is purely based on the prediction of how renewables will increase in the coming years. From this, it is visible that the emissions from these renewables are surely a major concern of harm to our environment. 


\section{IV - Conclusion}

The main objective of utilizing renewable energy resources is to make the planet a better place to live in, but with these effects caused, we are only delaying the inevitable. If we continue exploiting resources that harm our environment, we might be able to sustain life for a few decades, but if shift to these renewables we might be able to sustain life on our planet for at least a few decades. Although the shift to renewable energies can be a tedious task and also might seem to be impossible in the coming years, we must make an effort to be ready for this transition. By taking relevant steps we can curb the negative effects caused by these renewables and hence protecting our environment. We can control these by several methods:

- Selection of site for setup of renewables such that it has the least impact on the environment.

- Generate awareness towards the several renewable energy systems; implies that energies must be reign-specific.

- Governments around the globe must implement laws and policies to promote renewables and also set up a monitoring board to supervise renewable activities.

\section{References}

1. a, Kapil Kumar b, Naresh Kaushik c, Satyawati Sharma a, Saroj Mishra d Renewable energy in India: Current status and future potentials Ashwani Kumar (Published in Elsevier)

2. Website: Environmental Impacts of Renewable Energy Technologies | Union of Concerned Scientists (ucsusa.org)

3. Shitalkumar P. Patel, Supriya Shrivastava Environmental Impacts of Renewable Energy Technologies (National Conference on Emerging Trends in Mechanical Engineering)

4. Website: Here's How Renewable Energy Affects the Environment (greenmatters.com)

5. Website: Renewables And The Impact On Environment (electrical-engineering-portal.com)

6. Website: Renewable energy, facts and information (nationalgeographic.com)

7. Shahin Ansari a, Mr. Quazi T. Z b*, Dr. Fauzia Siddique c Assessment of Renewable Energy Sources (International Journal of Scientific \& Engineering Research, Volume 6, Issue 12)

8. Website: GLOBE-Net A Bright Future for Solar Energy - GLOBE-Net

9. Muhammad Adee, Jie Yinn, Lee Muhammad, Zain Muhammad Rizwan, Aamir Nawab, M.A. Ahmad, Muhammad Shafiq, Hao Yi, Ghulam Jilani Rabia Javed, R. Horton, Yukui Rui, Daniel C.W. Tsang, Baoshan Xing Cryptic footprints of rare earth elements on natural resources and living organisms (Published in Elsevier)

10. Table 1 - (Source: IEA (2016), Benign Energy. The Environmental Implications of Renewables, OECD/IEA) 
11. Mohammed Masum Low-Temperature Geothermal Systems in Sedimentary Basin and Their Prospect in Bangladesh 